\title{
Modulated Expression of Plasminogen Activator System Components in Cultured Cells from Dissociated Mouse Dorsal Root Ganglia
}

\author{
Steven M. Hayden and Nicholas W. Seeds \\ Neuroscience Program and the Department of Biochemistry, Biophysics, and Genetics, University of Colorado Health \\ Sciences Center, Denver, Colorado 80262
}

The development and regeneration of the peripheral nervous system (PNS) is highly dependent on the migration of Schwann cells and the extension of axons toward their distant targets. Plasminogen activators (PAs) are associated with the surface of several cell types of neural origin where they are believed to mediate localized degradation of extracellular matrix, thus facilitating cell motility. In this study, we characterize the expression of tissue-type (tPA) and urokinase (UPA) PAs, as well as the urokinase cell surface receptor (UPAR) during differentiation of cultured cells from mouse dorsal root ganglia. During the first day in culture, the mRNA levels of all three components increase from 75- to 163-fold, as shown using a quantitative PCR method. By $72 \mathrm{hr}$, the mRNA levels decrease and approach basal levels. This transient increase is in direct correlation with the differentiation of neurons and Schwann cells and the for- mation of a neuritic network in these regenerating cultures. Densitometric analysis of gel zymographs demonstrates that the elevation in mRNA levels is accompanied by similar increases in the activity levels of tPA and UPA. Interestingly, in situ hybridization studies of the cultures show that IPA mRNA is restricted to small sensory neurons, whereas UPA mRNA is localized predominantly in large sensory neurons. UPAR mRNA is expressed by both neuronal subpopulations and, to a lesser extent, by Schwann cells and fibroblasts. Taken together, these results further support a role for the PA system in facilitating axon extension and cell migration during development and regeneration of the PNS.

Key words: axon regeneration; sensory neurons; Schwann cells; tissue plasminogen activator; urokinase; urokinase receptor; quantitative polymerase chain reaction
The development and regeneration of the peripheral nervous system (PNS), including the movement of cells and their processes through tissues and extracellular matrices, may be mediated by the cellular secretion of plasminogen activators (PAs). Two types of PA have been identified in neuronal and non-neuronal systems: tissue PA (tPA) and urinary PA (uPA), often called urokinase. Although cell surface receptors specific for tPA have only been partially characterized (Verrall and Seeds, 1989; Hajjar et al., 1994), the uPA receptor (UPAR) has been purified (Behrendt et al., 1990), and the complete sequence of the murine uPAR gene has been determined (Suh et al., 1994). The uPA receptor is linked to the cell membrane by a glycosyl-phosphatidylinositol anchor (Ploug et al., 1991).

Evidence implicating PAs in the growth of the nervous system has been obtained from several studies. Initially, it was demonstrated from enzymatic studies that PA activity is in association with the growth cones of sensory neurons and with Schwann cells (Krystosek and Seeds, 1981, 1984; Krystosek et al., 1988), as well as sympathetic neurons (Pittman, 1985). Later studies showed that the addition of PA or PA inhibitors to cultures of neurons had profound effects on neurite outgrowth and the direction of

Received Aug. 31, 1995; revised Dec. 13, 1995; accepted Jan. 4, 1996.

This work was supported by Grant BNS $91-520917$ (N.W.S.) from the National Science Foundation and by National Institutes of Health Grants NS07083 and NS09304 (S.M.H.) and NS09818 (N.W.S.). We are grateful to Dr. Jay Degen for providing the uPA clone and Dr. Keld Dano for the UPAR clone. We also thank Dr. Jerry Clayton for his help with all aspects of image analysis.

Correspondence should be addressed to Dr. Nicholas W. Seeds, Director of the Neuroscience Program, University of Colorado Hcalth Sciences Center, 4200 East Ninth Avenue B-138, Denver, CO 80262.

Copyright $(1996$ Socicty for Neuroscicnce $0270-6474 / 96 / 162307-11 \$ 05.00 / 0$ cell migration (Hawkins and Seeds, 1986, 1989). The level of tPA enzymatic activity associated with Schwann cells has been found to increase after removal of neuronal cells from cultures of dissociated rat dorsal root ganglion (DRG) cells (Clark et al., 1991). Studies using in situ hybridization of tissue sections have demonstrated that urokinase mRNA is expressed by sensory neurons of DRG and by spinal cord motor neurons of the CNS, although no signal was detected in glial cells (Sumi et al., 1992). Recently, we have provided evidence for the uPA receptor on the surface of cultured cells from dissociated DRG (Seeds et al., 1992).

By analogy with other systems, the finding of PA activity in association with cultured sensory neurons and Schwann cells and the localization of PA mRNA to these cell types in tissue sections (Sumi ct al., 1992) implies that the PA system has importance in the motile events that occur during the development of the PNS. To further examine this possibility, a quantitative investigation of PA system component expression during neural differentiation of cultured DRG cells is warranted; however, no such studies have been undertaken to date. In this report, we describe the characterization of PA system component expression at both the enzymatic and mRNA level in cultures of differentiating neurons and Schwann cells from dissociated mouse DRG. To facilitate these studies, we have used gel zymography and have developed a quantitative reverse transcriptase PCR (RT-PCR) method for measuring the absolute amounts of tPA, uPA, and UPAR mRNA in samples of total RNA to determine whether these levels are upregulated during cellular differentiation. In addition, we have used in situ hybridization techniques to demonstrate the cell types in our cultures that express the PA system component mRNAs. Our findings show a modulated and differential expression of PA 
system components in cultures of dissociated DRG cells that can be positively correlated with the onset of cellular differentiation, the interaction of Schwann cells with extending neuritic processes, and the eventual formation of an axonal network.

\section{MATERIALS AND METHODS}

Cell culture. DRG from 1- to-2-d-old postnatal mice were collected in PBS containing $10 \mathrm{mM} \mathrm{HEPES}, \mathrm{pH} 7.4$, and $0.4 \%$ glucose, and treated for 30 min at $37^{\circ} \mathrm{C}$ with $0.25 \%$ trypsin. All procedures were conducted in accordance with the Animal Care Guidelines at the University of Colorado Health Sciences Center approved by National Institutes of Health. After trypsin treatment, the ganglia were rinsed with Eagle's basal media (Gibco, Gaithersburg, MD) containing $10 \mathrm{~mm}$ HEPES, $\mathrm{pH} 7.4$, and 5\% FBS (BEM/FBS) and dissociated to a single-cell suspension by 15 aspirations through a small-bore Pasteur pipette. The cells were collected by low-specd centrifugation, resuspended in BEM/FBS containing $25 \mathrm{ng} / \mathrm{ml}$ $2.5 \mathrm{~S}$ nerve growth factor, and plated onto fibronectin-coated (McGuire and Alexander, 1993) tissue culture dishes. After the indicated growth period, cells were processed for RNA isolation as described below. Cell cultures that were used for zymography were prepared identically, except that insulin, transferrin, selenium, and bovine serum albumin (ITS+; Collaborative Research, Bedford, MA) were used in place of serum. Axonal lengths were measured using an ocular micrometer and an Olympus CK inverted microscope (Olympus Optical, Tokyo, Japan). The rate of axonal growth $(\mu \mathrm{m} / \mathrm{hr})$ was taken as the change in mean axonal length divided by the change in time of culture.

$R N A$ isolation. Total RNA was isolated from cultured cells or intact DRG using RNAzol B (Tel-Test, Friendswood, TX) according to the manufacturer's directions. Purified RNA was treated with RNase-free DNase at $37^{\circ} \mathrm{C}$ for 30 min and then extracled with phenol/chloroform. Each sample of RNA was checked for genomic DNA contamination by PCR under the conditions described below, but without added reverse transcriptase (RI'). The RNA concentration was determined spectrophotometrically, and RNasin was added to a concentration of $100-150 \mathrm{U} / \mathrm{ml}$. If not used immediately, all RNA samples were stored at $-70^{\circ} \mathrm{C}$ in small aliquots.

Plasmids and primers. Plasmid pGuPA is the pGEM-11Zf( + ) vector (Promega, Madison, WI) containing a Pst $/$ SmaI fragment of mouse uPA cDNA, a gift from Dr. Jay Degen (University of Cincinnati Medical School, Cincinnati, OH). The insert includes $400 \mathrm{bp}$ of noncoding $3^{\prime}$ scquence (nuclcotides 1638-2039). Plasmid p50A/1 was a gift from Dr. Keld Dano (Finsen Laboratory, Copenhagen, Denmark) and is the pBluescript KS(+) vector (Stratagene Cloning Systems, La Jolla, CA) containing a $5^{\prime}$ XhoI fragment of mouse uPAR cDNA (nucleotides 1-366). Plasmid pGtPA contains a $515 \mathrm{bp} E c o$ RI/Pst I fragment of mouse tPA (nucleotides 805-1319) in the pGEM-3Z vector (Promega). The antisense uPA primer A (5'-AAGACCAAATGGCCCCGCATCACA-3') corresponds to uPA cDNA bases 1980-2003, and the sense uPA primer B (5'-TTTAGAAAACATCTCCTGGGCAAG-3') corresponds to uPA cDNA sequence 1644-1667. Primer C (5'-TGCTGCTGCTGCTGTTGCTGG-3') and primer D (5'-AACGGCCCTGAGGGAGAGC $\Lambda C-3^{\prime}$ ) are the sense and antisense primers for $u P \Lambda R$ CDNA, respectively. Primer $C$ corresponds to uPAR cDNA sequence $31-51$, and primer $D$ corresponds to sequence 336-356. The antisense tPA primer E (5'-AATGTCTGTTCTTCCTCTCCG-3') corresponds to tPA cDNA bases 1227-1247, and the sense tPA primer $F\left(5^{\prime}\right.$ GACCAACTCCCAGGCACTCGG-3') corresponds to tPA cDNA sequence $846-866$. Primer $G$ is a uPA sense primer and has the sequence 5'-TGTGATGCGGGGCCATTTGGTCTT-3'. Antisense primers used for PCR were also used as oligonucleotide probes for tPA, uPA, and uPAR in in situ hybridization studies. Sense primers were used as control oligonucleotide probes. In later experiments, primer $\mathrm{G}$ was used as a uPA sense control probe in in situ hybridizations and gave identical results as sense primer B. Primer G corresponded to uPA cDNA sequence 1980-2003. All primers were purchased from Research Genetics (IIuntsville, AL).

Reverse transcription. RNA mixtures were heated to $65^{\circ} \mathrm{C}$ and quickcooled on ice. Reverse transcription was performed for $10 \mathrm{~min}$ at room temperature followed by $45 \mathrm{~min}$ at $42^{\circ} \mathrm{C}$ in a total volume of $20 \mu \mathrm{l}$. The final concentrations in the reaction mixture were $10 \mathrm{~mm}$ Tris, pH $9.0,50$ $\mathrm{mm} \mathrm{KCl}, 0.1 \%$ Triton $\mathrm{X}-100,0.5 \mathrm{~mm}$ deoxynucleoside triphosphates (dNTP), $0.4 \mu \mathrm{g}$ random hexamer, $4 \mathrm{mM} \mathrm{MgCl}_{2}, 12 \mathrm{U}$ RNase inhibitor (RNasin; Promega), and $100 \mathrm{U}$ Moloney-murine leukemia virus RT
(Promega). After reverse transcription, the sample was heated to $94^{\circ} \mathrm{C}$ for 7 min to inactivate the enzyme.

$P C R$. cDNA mixtures were amplified with 20 pmol of primers in a total volume of $50 \mu \mathrm{l}$ and final concentrations of $10 \mathrm{~mm}$ Tris, $\mathrm{pH} 9.0,50 \mathrm{~mm}$ $\mathrm{KCl}, 0.1 \%$ Triton X-100, $0.2 \mathrm{~mm}$ dNTP, $1.6 \mathrm{~mm} \mathrm{MgCl}_{2}, 1 \mathrm{U}$ Taq DNA polymerase (Promega), and $40 \mu \mathrm{Ci} / \mathrm{ml} \quad\left[{ }^{32} \mathrm{P}\right]$ cytosine triphosphate ([ $\left.\left.{ }^{32} \mathrm{P}\right] \mathrm{dCTP} ; 3000 \mathrm{Ci} / \mathrm{mmol}\right)$. I lot-start PCR was used by adding to each tube containing reverse transcription reaction mixture an overlay of melted paraffin before addition of PCR components. The thermal cycler (Perkin-Elmer/Cetus, Norwalk, CT) profile consisted of 37 cycles at $94^{\circ} \mathrm{C}$ for $1 \mathrm{~min}, 60^{\circ} \mathrm{C}$ for $1 \mathrm{~min}$, and $72^{\circ} \mathrm{C}$ for $2 \mathrm{~min}$. After amplification, the mixture was heated for $7 \mathrm{~min}$ at $72^{\circ} \mathrm{C}$. To allow for maximum heteroduplex formation (Becker-Andre and Hahlbrock, 1989; Shoffner et al., 1990), the sample was then heated to $94^{\circ} \mathrm{C}$ for $5 \mathrm{~min}$ and allowed to cool to room temperature.

Site-directed mutagenesis. A unique $B c l$ site in the uPAR fragment of p50A/1 and unique $B g / I I$ sites in the inserts of pGtPA and pGuPA were the targets for restriction-site conversion via site-directed mutagenesis. Plasmid p50A/ 1 was digested with $B c l \mathrm{I}$, and plasmids pGtPA and $\mathrm{pGuPA}$ were digested with $B g I I$. The resultant staggered ends of the linearized plasmids were filled in with the Klenow fragment of DNA polymerase (Promega), and the plasmid DNA was then recircularized by blunt-end ligation with T4 DNA ligase (Promega). The new constructs each contained a 4 bp addition, which results in the elimination of the original restriction sites and the formation of unique $\mathrm{ClaI}$ sites. The mutated constructs were then used as templates for in vitro transcription using T7 or SP6 RNA polymerase to generate internal standard RNAs specific for uPAR, tPA, and UPA target mRNA.

Quantitative RT-PCR. Increasing amounts of internal standard RNA were added to fixed amounts of total RNA, and the mixture was amplified as described above. PCR products obtained from internal standards were distinguished from those obtained from target mRNA by digestion with $\mathrm{ClaI}$ and were analyzed by electrophoresis on $2.3 \%$ agarose gels. The radioactivity in bands was determined by liquid scintillation counting. To correct for differences in the size of PCR products, the amount of radioactivity in the internal standard bands on the gels was multiplied by the ratio of target/internal standard base pair fragment size. All values for target mRNA levels were calculated after correction for heteroduplex formation (Becker-Andre and Hahlbrock, 1989; Shoffner et al., 1990). For studies demonstrating the accuracy of the quantitative RT-PCR method, target RNA was generated by in vitro transcription of the UPA and UPAR fragments in pGuPA and p50A/1, respectively, and concentrations were determincd spectrophotometrically.

In situ hybridization. Cultures of dissociated DRG were rinsed with PBS and fixed for $10 \mathrm{~min}$ at room temperature with freshly prepared $4 \%$ paraformaldehyde. After a rinse with PBS, the cultures were permeabilized with $0.2 \mathrm{~N} \mathrm{HCl}$ for $10 \mathrm{~min}$ and acetylatcd $10 \mathrm{~min}$ with $0.25 \%$ acetic anhydride in $0.1 \mathrm{M}$ triethanol-amine, $\mathrm{pH} 8.0$. In double-labeling experiments using neuron-specific enolase, $0.5 \%$ Triton $\mathrm{X}-100$ was substituted for $0.2 \mathrm{~N} \mathrm{HCl}$. After washing with $1 \times \mathrm{SSC}$, the coverslips were prehybridized with $4 \times$ SSC, $25 \%$ formamide, $5 \times$ Denhardt's reagent, $100 \mathrm{U} / \mathrm{ml}$ RNasin, $0.5 \mathrm{mg} / \mathrm{ml}$ tRNA, and $10 \mathrm{~mm}$ dithiothreitol (DTT) for $3 \mathrm{hr}$ at room temperature and then hybridized with the same solution containing $1 \times 10^{7} \mathrm{cpm} / \mathrm{ml}$ of probe that had been end-labeled with $\left[{ }^{35} \mathrm{~S}\right] \mathrm{dATP}$ $(>1000 \mathrm{Ci} / \mathrm{mmol}$ ) using terminal transferase (Boehringer Mannheim, Indianapolis, IN) according to the manufacturer's instructions. Humidified chambers were used for all hybridizations that lasted $18 \mathrm{hr}$ at $37^{\circ} \mathrm{C}$ when the uPAR probe was used, and $18 \mathrm{hr}$ at $30^{\circ} \mathrm{C}$ when the uPA and tPA probes were used. After hybridization, the coverslips were washed in $1 \times$ SSC, $1 \mathrm{~mm}$ DTT for $30 \mathrm{~min}$ at room temperature, and then subjected to two 30 min washes in the same buffer at the hybridization temperature. After the washes, the coverslips were dehydrated with 5 min rinses in $50 \%$ ethanol, $1 \times$ SSC, $1 \mathrm{mM}$ DTT; $70 \%$ ethanol, $0.1 \times$ SSC, $1 \mathrm{mM} \mathrm{DTT;} 95 \%$ ethanol; and three rinses with $100 \%$ ethanol. After air drying, cultures that had been incubated with UPAR probes were further treated for immunocytochemistry (see below), whereas coverslips that had been hybridized with $\mathrm{uPA}$ and $\mathrm{PPA}$ probes were treated with Kodak liquid emulsion NTB-2 (Rochester, NY) and exposed in the dark for 2-3 weeks. As negative controls, $\left[{ }^{32} \mathrm{~S}\right]$-labeled sense probes were used and showed only background signals. For quantitation, negative film was digitized using a UMAX flatbed scanner (UMAX Technologies, Freemont, CA) equipped with a transparency adaptor. Images obtained were reversed and then analyzed using National Institutes of Health Image software version 1.58. All data were corrected for background and expressed as average grain density. 
Immunocytochemistry. Cultures that had been hybridized with $\mathrm{UPAR}$ $\left[{ }^{35} \mathrm{~S}\right]$-labeled probes were washed in $1 \times$ SSC, $1 \mathrm{~mm}$ DTT for $30 \mathrm{~min}$ at room temperature and then subjected to two $30 \mathrm{~min}$ washes in the same buffer at $37^{\circ} \mathrm{C}$. The coverslips were then rinsed with PBS, treated for 20 min with $1 \%$ goat serum, and incubated for $1 \mathrm{hr}$ with a prediluted solution of rabbit polyclonal antiserum raised against neuron-specific enolase (Zymcd, South San Francisco, CA). After rinsing several times with PBS, the cultures were incubated for $30 \mathrm{~min}$ with a solution of biotinylated goat anti-rabbit IgG (Vector Laboratories, Burlingame, CA), washed with $\mathrm{PBS}$, and treated for $60 \mathrm{~min}$ with a peroxidase-conjugated $\mathrm{ABC}$ avidinbiotin complex (Vector Laboratories). The coverslips were then developed with a solution of $0.5 \mathrm{mg} / \mathrm{ml}$ diaminobenzidine (DAB; Sigma, St. Louis, $\mathrm{MO}$ ), $0.01 \% \mathrm{H}_{2} \mathrm{O}_{2}$ in $0.1 \mathrm{M}$ Tris, $\mathrm{pH}$ 7.2. After dehydration through graded alcohol, the coverslips were finally treated with Kodak liquid emulsion NTB-2 with exposure times between 2 and 3 weeks. Negative controls included $\left[{ }^{35} \mathrm{~S}\right]$-labeled uPAR sense probes, which showed no signals.

SDS-PAGE gel zymography. The PAs were identified by gel zymography as described by Heussen and Dowdle (1980). Conditioned media from cultures grown for various times were removed, and cell layers were solubilizcd in an cqual volume of $0.1 \mathrm{M}$ Tris, $\mathrm{pH} 8.1,0.2 \%$ Triton X-100. Protein content of the cell extracts was determined using a BCA Protein Assay Kit (Pierce, Rockford, IL) according to the manufacturer's instructions. The same amount of total protein from each cell extract sample and an equal volume of the corresponding conditioned media were then applied to polyacrylamide gels that had been copolymerized with casein $(1 \mathrm{mg} / \mathrm{ml}$; Sigma) and plasminogen $(0.04 \mathrm{U} / \mathrm{ml}$; Cromogenix AB, Molndal, Sweden). Control gels were prepared similarly but without added plasminogen. After nonreducing SDS-PAGE, the gels were treated with $2.5 \%$ Triton $\mathrm{X}-100$, rinsed with water, and soaked in $0.1 \mathrm{M}$ Tris, $\mathrm{pH} 8.1$, at $37^{\circ} \mathrm{C}$. After $16 \mathrm{hr}$, the gels were stained in $0.125 \%$ Coomassie blue in $50 \%$ methanol $10 \%$ acetic acid, and destained in the same solvent. Zones of proteolytic activity that appeared as clear bands against a Coomassic blue-stained background were analyzed using a Molecular Dynamics Computing Densitometer (Sunnyvale, CA).

Immunoblotting. Cell layers from cultures grown for various times were solubilized with $50 \mathrm{~mm}$ Tris, $\mathrm{pH} 7.4,0.1 \%$ SDS, $0.1 \%$ Triton X-100. The protein content of the cell extracts was determined using a BCA Protein Assay Kit (Pierce), and $6 \mu \mathrm{g}$ of each sample were blotted to nitrocellulose using a dot blot apparatus (Bio-Rad, Richmond, CA) according to the manufacturer's instructions. The nitrocellulose was removed from the apparatus, blocked with $1 \%$ bovine serum albumin in PBS, and incubated overnight with a prediluted solution of monoclonal antibody raised against the middle and high molecular weight neurofilament proteins (Zymed). After several rinses with PBS, the blots were incubated with a solution of biotinylated horse anti-mouse $\operatorname{IgG}$ (Vector Laboratories) and washed with PBS. After treatment with an $\mathrm{ABC}$ avidin-biotin complex (Vector Laboratories), the blots were again rinsed with PBS and developcd with a solution of $0.5 \mathrm{mg} / \mathrm{ml} \mathrm{DAB}, 0.01 \% \mathrm{H}_{2} \mathrm{O}_{2}, 0.03 \% \mathrm{NiCl}_{2}$ in $0.1 \mathrm{M}$ Tris, $\mathrm{pH} 7.2$.

\section{RESULTS}

\section{Cultures of dissociated DRG cells}

PA proteolytic activity is found associated with the growth cones of sensory (Krystosek and Seeds, 1984) and sympathetic neurons (Pittman, 1985) and with the cellular processes of Schwann cells (Krystosek and Seeds, 1984; Krystosek et al., 1988). By analogy with other systems, this finding is believed to reflect a role for PAs in the growth and differentiation of these cell types during nervous system development and reorganization. To further examine the functional significance of the PA system, we studied the expression of the PA system components TPA, uPA, and UPAR during the growth of cultured cells obtained from DRG.

Mechanical dissociation of DRGs yielded a preparation comprised primarily of sensory neurons and Schwann cells with fewer numbers of fibroblasts. As shown in Figure 1, immediately after dissociation, neurons could be easily identified by their rounded morphology and bright cytoplasm when viewed with phase-contrast optics. Occasionally, neurons with a truncated axonal process were also observed. After $8 \mathrm{hr}$ in culture, fibroblasts had become flattened and Schwann cells appeared spindle-like. At this stage, both neurons and non-neuronal cells were attached to the substratum, and Schwann cells were often observed in contact with the axons that had begun to regenerate from sensory neurons. By $20 \mathrm{hr}$ in culture, the growth of cellular processes increased, so that by $27 \mathrm{hr}$, an extensive neural network had developed that was comprised of Schwann cells aligned and associated wilh axonal processes. After 45 hr, the proliferating populations of Schwann cells and fibroblasts were more apparent, whereas the rapid growth of axons from sensory neurons had clearly diminished. After $72 \mathrm{hr}$, the start of a monolayer of non-neuronal cells was visible under the established network of axons (Fig. 1). Two methods were used to characterize the development of the axonal network in the cultures. As an indicator of the extent of axonal outgrowth, the level of middle and high molecular weight neurofilament protein in the cultures was examined. Immunoblot analyses showed that the level of neurofilament protein increased rapidly during the first $20 \mathrm{hr}$ of culture before reaching a plateau (Fig. 2). Similarly, direct measurements of axonal lengths showed that the highest average rates of axonal outgrowth occurred in the 20 and $27 \mathrm{hr}$ cultures (Fig. 3). Although axons were maintained (Fig. $3 A$ ), a rapid decline in rate of outgrowth (Fig. $3 B$ ) was apparent in the 45 and 72 hr cultures.

\section{Quantitative RT-PCR}

As a first step in characterizing the expression of PA system components in the cultures of dissociated DRG, we were interested in determining whether the mRNA levels of tPA, uPA, and uPAR were upregulated during the onset of axonal outgrowth and cellular differentiation. The traditional methods of Northern hybridization and RNase protection to measure mRNA levels were found to be impractical, however, because of low copy numbers and the limited number of cells obtained from standard size cultures of dissociated DRG. Reverse transcription of RNA samples followed by PCR is a technique that is often used as a sensitive method for detecting mRNA species from limited amounts of total RNA. However, as a quantitative tool, RT-PCR is usually considered unreliable. The exponential nature of the amplification process is such that small differences in reaction efficiencies result in very large differences in the final amount of product. This problem can be overcome by using a procedure in which target cDNA is competitively coamplified with an internal standard cDNA that shares sites for primer annealing (Gilliland et al., 1990). After amplification, the PCR products are distinguished by differences in size or by an engineered restriction site unique to the internal standard cDNA. In our hands, the quantitative PCR procedure was found to be very reliable and offered a means to easily detect and measure femtogram amounts of tPA, uPA, and uPAR target mRNA from dissociated DRG cell cultures of standard size.

The quantitative RT-PCR method that was developed for these studies consisted of adding increasing amounts of internal standard to a sample of extracted total RNA containing the target mRNA. Internal standard RNAs were generated by in vitro transcription of cDNA fragments that had been altered at a single restriction site by site-directed mutagenesis (see Materials and Methods). Figure 4 shows a typical quantitation of target mRNA using RT-PCR. After RT and amplification in the presence of $\left[{ }^{32} \mathrm{P}\right] \mathrm{dCTP}, \mathrm{PCR}$ products obtained from target and internal standard RNA were treated with ClaI restriction enzyme and resolved by gel electrophoresis (Fig. $4 A$ ). The radioactivity in the bands was measured by scintillation counting, and a value for the amount of target mRNA was calculated from plots of the log of internal standard/target counts per minute versus the log of internal standard added (Fig. 4B). In experiments using known 

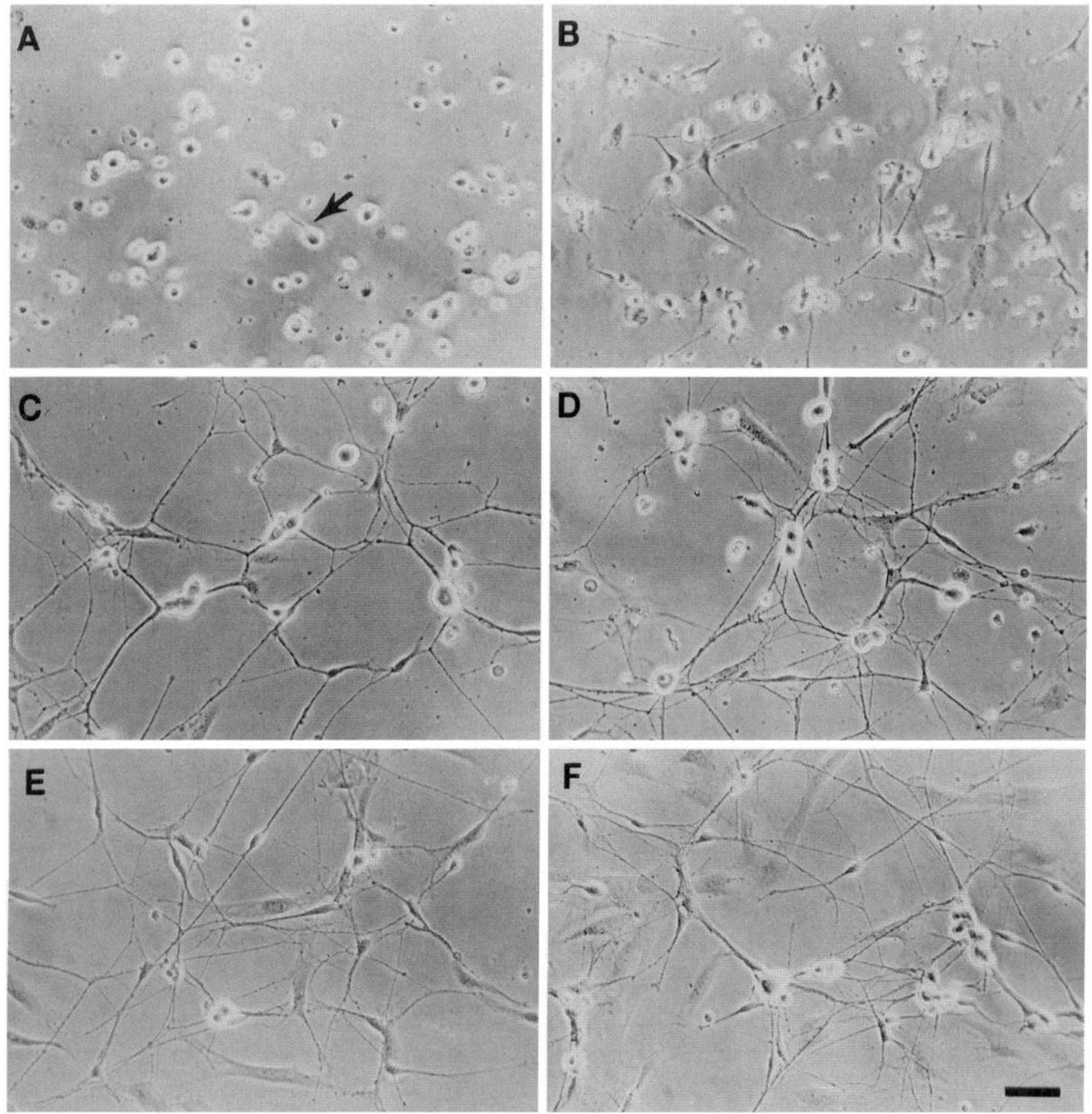

Figure 1. Phase-contrast micrographs of cultures of dissociated mouse DRG. A, Cultured DRG cells 30 min after dissociation. Neurons appear as round phase bright cells and are occasionally observed with a truncated axon (arrow). B, Ganglion cells after $8 \mathrm{hr}$ in culture. Schwann cells appear spindle-like and in contact with axons that have begun to regenerate from neurons. $C$, DRG cells $20 \mathrm{hr}$ after plating. An axonal network begins to form with associated Schwann cells. $D$, Ganglion cells cultured for $27 \mathrm{hr}$. A dense network of axons is observed. $E$, Cultured ganglion cells $45 \mathrm{hr}$ after plating. The rate of growth of axons from sensory neurons has diminished. F, DRG cells grown for $72 \mathrm{hr}$. Subpopulations of Schwann cells and fibroblasts have become more apparent. Scale bar, $50 \mu \mathrm{m}$.

amounts of target mRNA, the method was determined to be accurate over at least a 1000 -fold range of target concentrations (Fig. 4C).

\section{Levels of tPA, UPA, and uPAR mRNA in cultured cells}

Using quantitative RT-PCR, it was found that the levels of tPA, uPA, and UPAR mRNAs increased transiently in cultures of DRG cells after dissociation (Fig. 5). The increases in mRNA levels and the maximal amounts detected correlated well with the time course for the onset of axon extension and cellular differentiation (Fig. 1). The levels of all three mRNAs increased substantially with maximal levels detected after $20-27 \mathrm{hr}$ of incubation. The highest level measured for tPA mRNA represented a 75 -fold increase, from a basal level of $0.051 \mathrm{fmol} / \mathrm{mg}$ RNA $(n=3)$ immediately after dissociation to a level of $3.80 \mathrm{fmol} / \mathrm{mg}$ RNA $(n=3)$ determined at $27 \mathrm{hr}$. Urokinase 


\section{Culture Period}

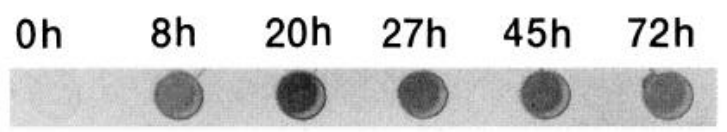

Figure 2. Middle and high $(\mathrm{M}+\mathrm{H})$ molecular weight neurofilament protein in cultures of dissociated mouse DRG. Total protein was extracted from cultures of dissociated DRG at the times indicated, and the level of neurofilament protein $(\mathrm{M}+\mathrm{H})$ was examined by immunoblot analysis. An equal amount of total protein $(6 \mu \mathrm{g})$ was analyzed for each time point. The experiment was repeated twice with similar results.

mRNA levels rose from a measured level of $0.076 \mathrm{fmol} / \mathrm{mg}(n=3)$ to $8.21 \mathrm{fmol} / \mathrm{mg}$ RNA $(n=3)$ at $20 \mathrm{hr}$, a 108-fold increase. The largest change measured was that for the UPAR mRNA, with an increase of 163 -fold, from a value of $0.26 \mathrm{fmol} / \mathrm{mg} \mathrm{RNA}(n=3)$ at $0 \mathrm{hr}$ to $42.5 \mathrm{fmol} / \mathrm{mg} \mathrm{RNA}(n=3)$ after $27 \mathrm{hr}$ of incubation.

The gelatin-binding fragment of fibronectin has been reported to cause a threefold increase in the expression of urokinase mRNA from endocardial-derived cells. This increase is accompanied by changes in cell morphology and behavior (McGuire and Alexander, 1993). To ensure that the change we detected in uPA mRNA levels in our cultures was not a consequence of substratum effects alone, we plated dissociated cells on different matrix components and used quantitative RT-PCR to determine uPA mRNA levels after $20 \mathrm{hr}$ of growth. No significant differences were detected in mRNA levels in samples of total RNA obtained from cells cultured on fibronectin, collagen, laminin, poly-D-lysine, or tissue culture plastic. Similar results were obtained when uPAR mRNA levels were measured (data not shown).

\section{tPA and uPA proteolytic activity}

To determine whether the alterations that were observed in tPA and UPA mRNA levels in dissociated DRG cultures are accompanied by similar changes in PA activity, serum-free conditioned media and cellular extracts were collected at different times from cultures grown for a total of $72 \mathrm{hr}$, and the relative level of total PA activity was determined by densitometric analysis of zymography gels (Fig. 6). Only very low levels of uPA and tPA activity could be detected in cell extracts immediately after dissociation, in agreement with the basal levels of mRNA detected at this time point. Throughout the time course, approximately equal amounts of uPA activity were detected in the cell-associated and conditioned media fractions, whereas IPA activity was primarily cell-associated during the early stages of the time course and only appeared in the conditioned media at later stages. It should be noted that cell-associated activity in these experiments represents both extracellular membrane-bound PA activity and PA activity localized intracellularly. When the data obtained from densitometric analyses were plotted as total uPA and tPA activity versus time, a substantial elevation in total activity $(60 \%$ of maximal) was observed at $8 \mathrm{hr}$, which continued to increase to a maximum after $27 \mathrm{hr}$ for uPA and after $45 \mathrm{hr}$ for tPA. Interestingly, at the $27 \mathrm{hr}$ time point a band that corresponded to the tPA/PA inhibitor (PAI) complex became apparent and remained visible throughout the remaining time course. By 72 $\mathrm{hr}$, the activity levels of both uPA and tPA declined to $\sim 40 \%$ of their maximal values (Fig. $6 B$ ). Thus, the time-course profile
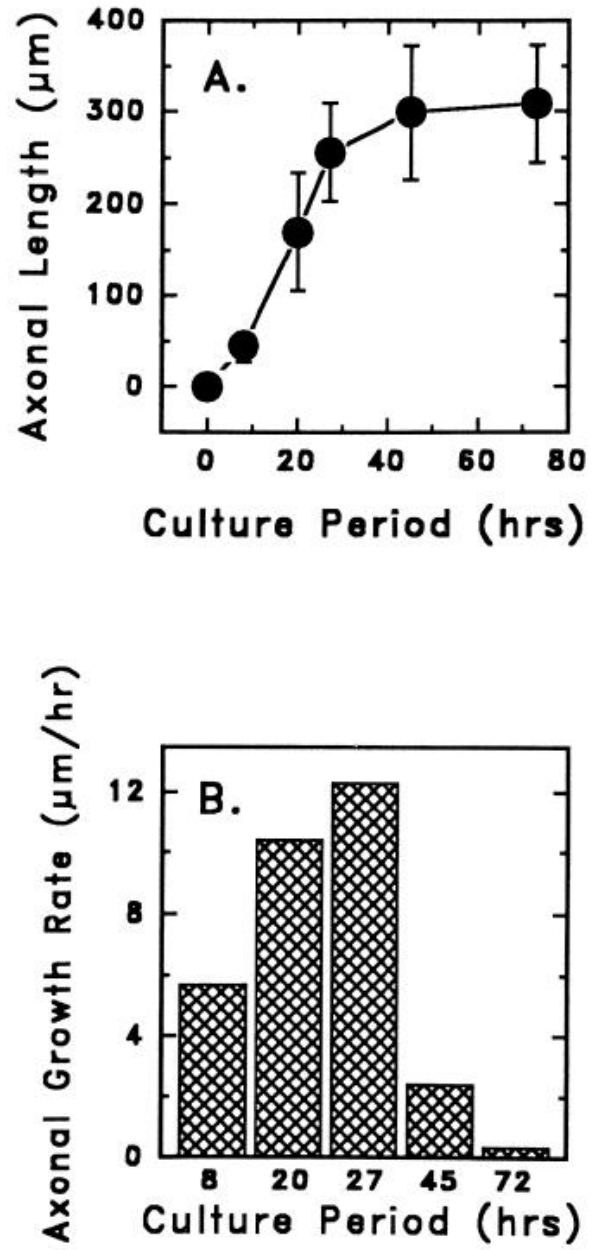

Figure 3. A, Length of axons in cultures of dissociated DRG. Axonal lengths from at least 25 neurons were measured at each of the times indicated (mean $\pm \mathrm{SEM})$. Axonal length immediately after dissociation $(0$ hr) was assigned a value of zero. $B$, Rate of axonal outgrowth in cultures of dissociated DRG. The rate of axonal growth $(\mu \mathrm{m} / \mathrm{hr})$ was determined by the change in mean axonal length divided by the change in time of culture and is plotted against the culture period.

obtained for the increase in total uPA and tPA proteolytic activity correlated well with the transient increases that were observed during the time course for their mRNA levels.

\section{Cellular localization of tPA, uPA, and uPAR mRNA}

To identify the cell types that express the mRNAs of the PA system, DRG dissociates were cultured for $24 \mathrm{hr}$ and then hybridized to $\left[{ }^{35} \mathrm{~S}\right]$-labeled oligonucleotide antisense probes. Figures 7 and 8 show that the relative intensity of the signals from these in situ hybridization studies was in agreement with the measurements obtained by quantitative RT-PCR for mRNA levels: a strong signal was obtained from in situ hybridization when the UPAR probe was used, whereas weaker signals were detected using the tPA and uPA probes. The expression of uPA mRNA appeared to be restricted to the larger ( $\geq 20 \mu \mathrm{m}$ diameter) neurons in the cultures, although occasionally small or medium-sized neurons were found to be very weakly labeled by the uPA probe (Fig. $7 D$ ). tPA mRNA signal was detected primarily in a subpopulation of neurons of smaller $(<12 \mu \mathrm{m}$ diameter) size (Fig. $7 H)$. Quantitation of digitized images from the in situ hybridization results showed a significant increase in grain density associated 
A

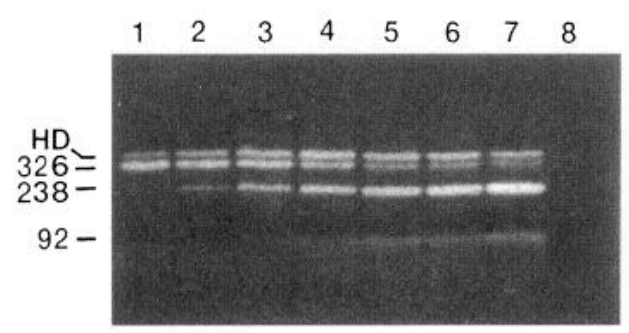

B

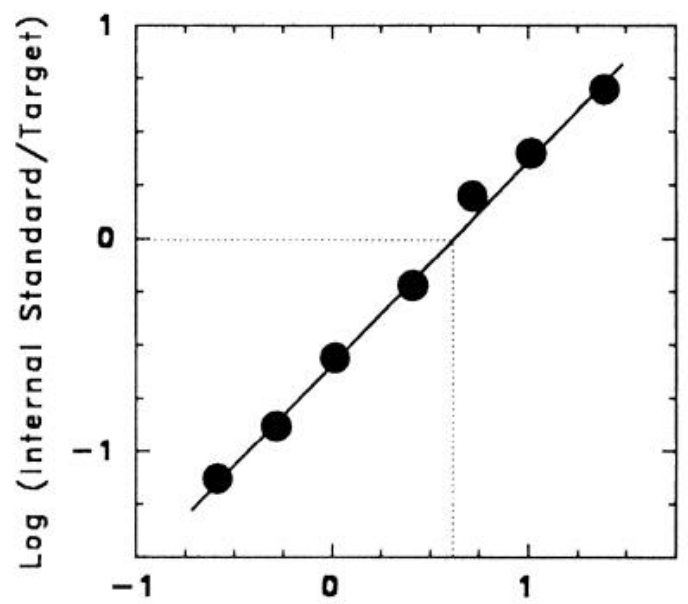

Log Internal Standard (amoles)

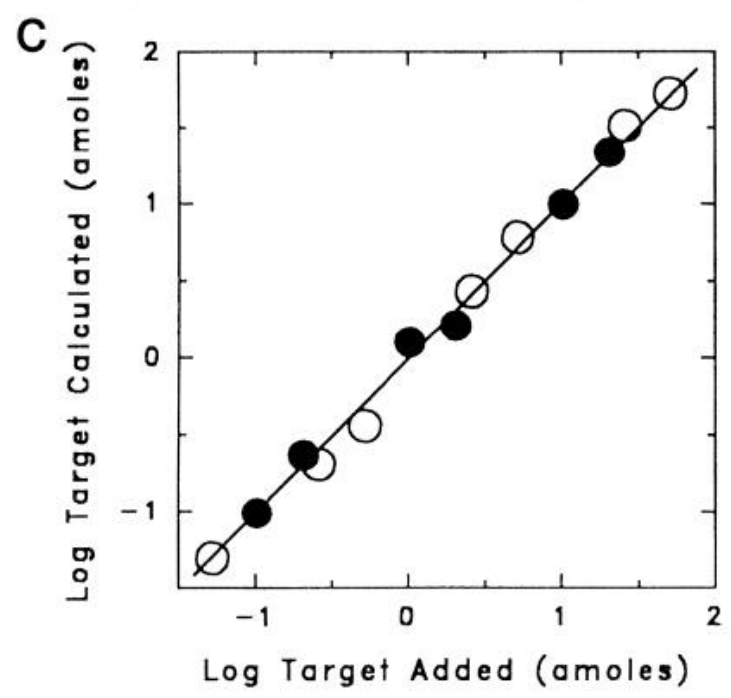

Figure 4. Quantitative analysis of mouse UPAR mRNA. Increasing amounts (lanes 1-7) of UPAR internal standard RNA were added to a sample of total RNA obtained from cultures of dissociated DRG, and the mixture was subjected to quantitative RT-PCR with $\left[{ }^{32} \mathrm{P}\right] \mathrm{dCTP}$ as described in Materials and Methods. $A$, Representative agarose gel showing the products obtained after digestion of RT-PCR products with ClaI. A control sample (lane 8 ) was prepared without RNA. The 326 bp product is the predicted $\mathrm{Cla}$ I-resistant fragment obtained from amplification of the uPAR mRNA target. The 238 and 92 bp fragments are the predicted products obtained after amplification of the UPAR internal standard and digestion with ClaI. $H D$ represents the $C l a \mathrm{I}$-resistant heteroduplex formed from the annealing of single strands from target and internal standard PCR products. $B$, Graphical representation of data obtained from $A$. Bands corresponding to the HD +326 bp fragment and the $238 \mathrm{bp}$ fragment were excised from the gel, and radioactivity was determined by liquid scintillation counting. The amount of radioactivity measured for the $\mathrm{HD}+326$ bp fragment was multiplied by the ratio $238 / 326$ to correct for the difference in PCR product size. The value of added internal standard at which the ratio of internal standard/target is equal to unity $(\log =0$; shown by dotted line) is taken as the amount of target mRNA in the sample of total RNA. $C$, Relationship between actual and measured target RNA with large neurons in cultures hybridized with the uPA probe and a similar increase in grain density associated with small neurons from cultures hybridized to the tPA probe (Table 1). Signal for uPA and tPA was rarely found to be above background in Schwann cells and fibroblasts. Control cultures incubated with sense probes (Fig. $7 B, F$ ) showed only weak "edge effect" labeling artifacts around most of the cells. As shown in Figure 8, hybridization of the cultures with antisense UPAR probes resulted in strong signals in association with both the large and small neuronal subpopulations. Because of the greater intensity of the UPAR signal compared with uPA and tPA signals, it was possible to confirm the neuronal nature of these subpopulations by doublelabeling with neuron-specific enolase (Fig. 8D). Schwann cells and the occasional fibroblast were also found to express uPAR mRNA, but to a much lesser extent than the neuronal cells (Fig. $8 D$ ). Thus, the uPA and tPA mRNAs appear to be differentially expressed by distinct subpopulations of neuronal cells, whereas the UPAR mRNA is expressed by virtually all cell types in the cultures.

\section{DISCUSSION}

In this report, we show that the mRNA levels of the PA system components tPA, uPA, and UPAR increase substantially but transiently during the initial stages of axonal regeneration in cultures of cells from dissociated DRG. Subpopulations of neurons differentially express either uPA or tPA messages, whereas UPAR mRNA is expressed by most of the ganglion cells in culture. The increases in the mRNA levels of the tPA, uPA, and UPAR are accompanied by similar elevations in the levels of tPA and UPA proteolytic activity. The transient increases in PA system component mRNA and catalytic activities parallels the time course for the DRG cells to establish a network of axons in association with Schwann cells. To our knowledge, this is the first report of a positive correlation between PA system component expression and the differentiation of ganglion cells, and provides additional evidence in support of a role for the PA system in mediating neuronal and glial cell motility during PNS development and regeneration.

Increases in PA activity resembling those described in this study have previously been found to be linked with cellular proliferation (Kalderon, 1984; Kirchheimer et al., 1987). Although proliferation of the Schwann cell and fibroblast populations in our cultures does occur in parallel with the mRNA and activity increases we observe in PA system components, the labeling of postmitotic neurons with uPA and tPA probes in in situ hybridization studies and the weak or absent mRNA signal in the dividing populations of Schwann cells and fibroblasts are inconsistent with the PA system having a primary function in proliferation. This is supported by studies of astrocytes in which no straightforward correlation could be demonstrated between PA activity and the growth factor-stimulated proliferation of astrocytes (Rogister et al., 1988; Tranque et al., 1994). Thus, we believe that the increases we observe in the activity and mRNA levels of uPA and tPA in

\footnotetext{
$\leftarrow$

using quantitative RT-PCR. RNA obtained from in vitro transcription of the inserts in plasmids pGuPA and $\mathrm{p} 50 \mathrm{~A} / 1$ (see Materials and Methods) was used as target RNA for uPA $(\bigcirc)$ and uPAR $(\bullet)$, respectively. Known amounts of the target RNA over the range shown were quantified with RT-PCR as described for uPAR mRNA in $A$ and $B$. The log of the amount of target calculated using quantitative PCR is plotted against the log of the actual amount of target added.
} 


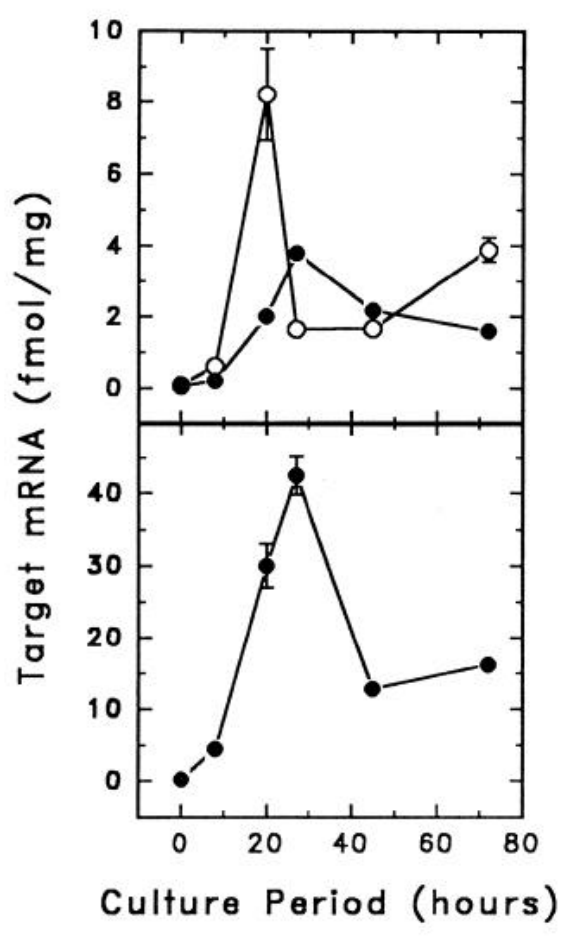

Figure 5. Time course of uPA, tPA, and uPAR mRNA induction in cultures of dissociated DRG. Total RNA was extracted from cultures of dissociated DRG at the times indicated. The absolute amounts of uPA $(O)$ and tPA (-) (top panel), or the absolute amount of uPAR (bottom panel) mRNA was determined by quantitative RT-PCR, and values were expressed as fmol/mg total RNA (mean $\pm \mathrm{SEM} ; n=3$; error bars smaller than figure symbols are not shown).

cultures of dissociated DRG are the result of their role in processes related to cell motility rather than cellular proliferation.

Although the elevation in PA mRNA levels and proteolytic activities were both transient, the kinetics for induction differed substantially during the initial stages of the time course. tPA and uPA activities rose to $60 \%$ of the maximal level within $8 \mathrm{hr}$ of culture, whereas the increase measured for their corresponding mRNA levels during this time period represented only $10 \%$ of the maximal values. Typically, a discrepancy between activity and mRNA levels suggests that post-transcriptional control mechanisms may be in effect. In this respect, substantial increases in activity levels without corresponding increases in mRNA levels have been described for tPA expression in mouse oocytes and are believed to be the result of such post-transcriptional modulation (Huarte et al., 1987). On the other hand, PAIs have been shown to be an important component of the PA system in regulating the extent of PA proteolysis and are believed responsible for the large discrepancy that exists between TPA mRNA and tPA proteolytic activity in adult murine brain (Sappino et al., 1993). In the study presented here, a decrease in the maximal activity of PA by inhibitors would give the impression of larger relative amounts of PA activity at other time points and would result in the relatively broad time-course curves that are observed. In support of this possibility, close examination of the gel in Figure 6 shows that a high molecular weight tPA/PAI complex is indeed detectable after $20 \mathrm{hr}$ in culture and remains visible throughout the remainder of the time course. It should be noted that because only partially dissociated PA/PAI complexes are detected on zymographs, the actual amount of the complex is likely to be largely underesti-
A
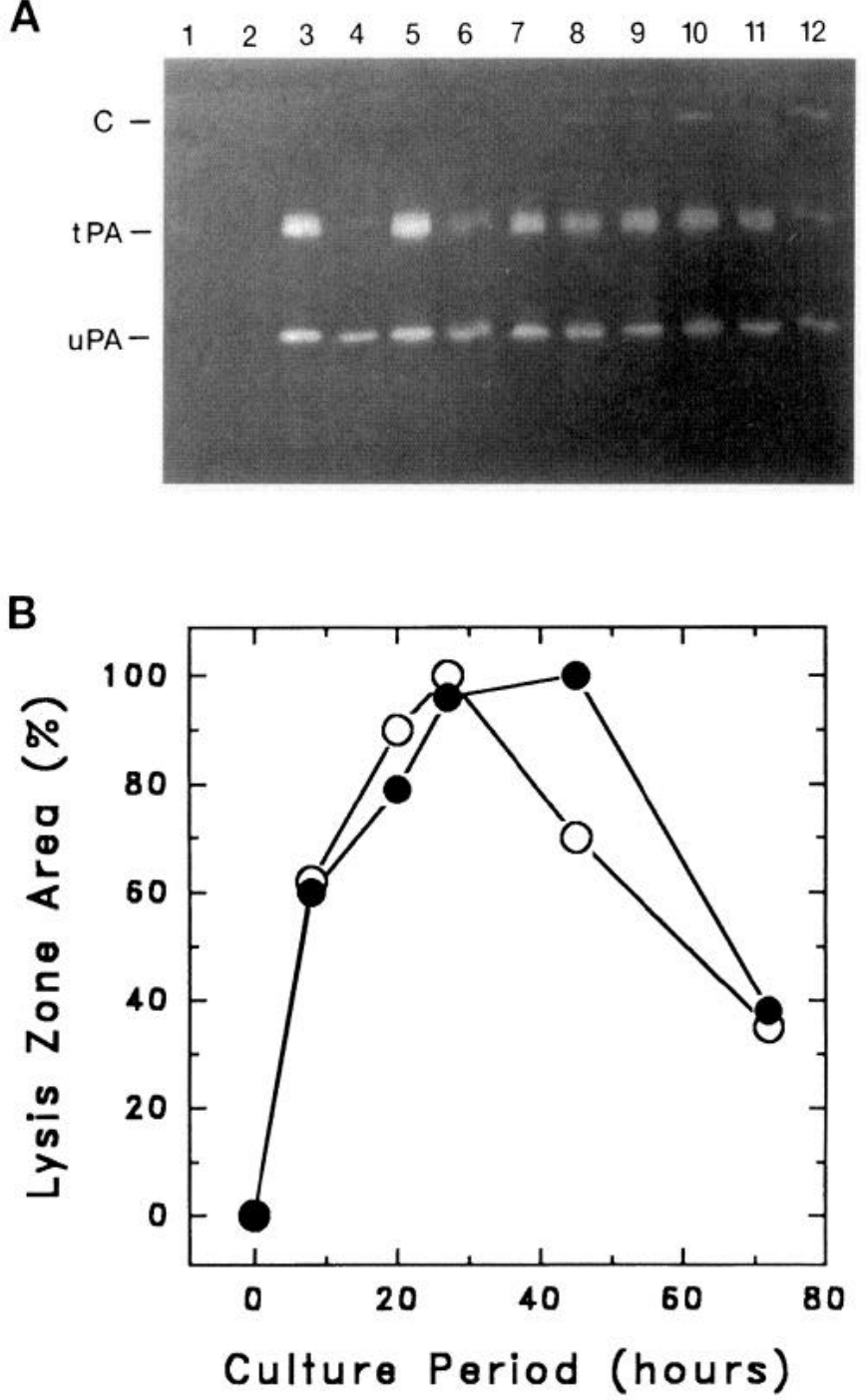

Figure 6. Time-course analysis of uPA and tPA activity in cultures of dissociated DRG. $A$, Samples of cell extracts (lanes 1,3,5,7,9,11) and conditioned media (lanes 2,4,6,8,10,12) from cultures of dissociated DRG were obtained after periods of $0 \mathrm{hr}(1,2), 8 \mathrm{hr}(3,4), 20 \mathrm{hr}(5,6), 27 \mathrm{hr}(7,8)$, $45 \mathrm{hr}(9,10)$, or $72 \mathrm{hr}(11,12)$ and analyzed by gel zymography. Band positions for tPA, uPA, and the tPA/PAI complex $(C)$ are shown. $B$, Densitometric scanning analysis of the zymograph shown in $A$. Values for uPA $(O)$ and tPA $(\bullet)$ total activity (cell extracts + conditioned media) are expressed as the area of lysis cleared on the gel (mean \pm SEM; $n=3$; error bars smaller than figure symbols are not shown). Maximum values obtained for lysis zone area were taken as $100 \%$. Although visible on the original zymograph in $A$, bands corresponding to uPA and tPA activity at the $0 \mathrm{hr}$ time point were too faint to be accurately quantitated by densitometric scanning and were given a value of zero.

mated by visual examination of the PA/PAI band on the gel. With respect to $\mathrm{uPA}$, the lack of a band corresponding to a similar uPA/inhibitor complex may be explained by the rapid internalization and degradation of such complexes after they are formed and bind to uPAR on the cell surface (Nykjaer et al., 1992; Olson et al., 1992; Orth et al., 1992). Alternatively, it also may be that the control of uPA activity is largely mediated via activation of accumulated stores of the uPA zymogen pro-uPA (Saksela and Rifken, 1988), which would result in a rapid increase in uPA activity levels without corresponding increases in mRNA levels. 

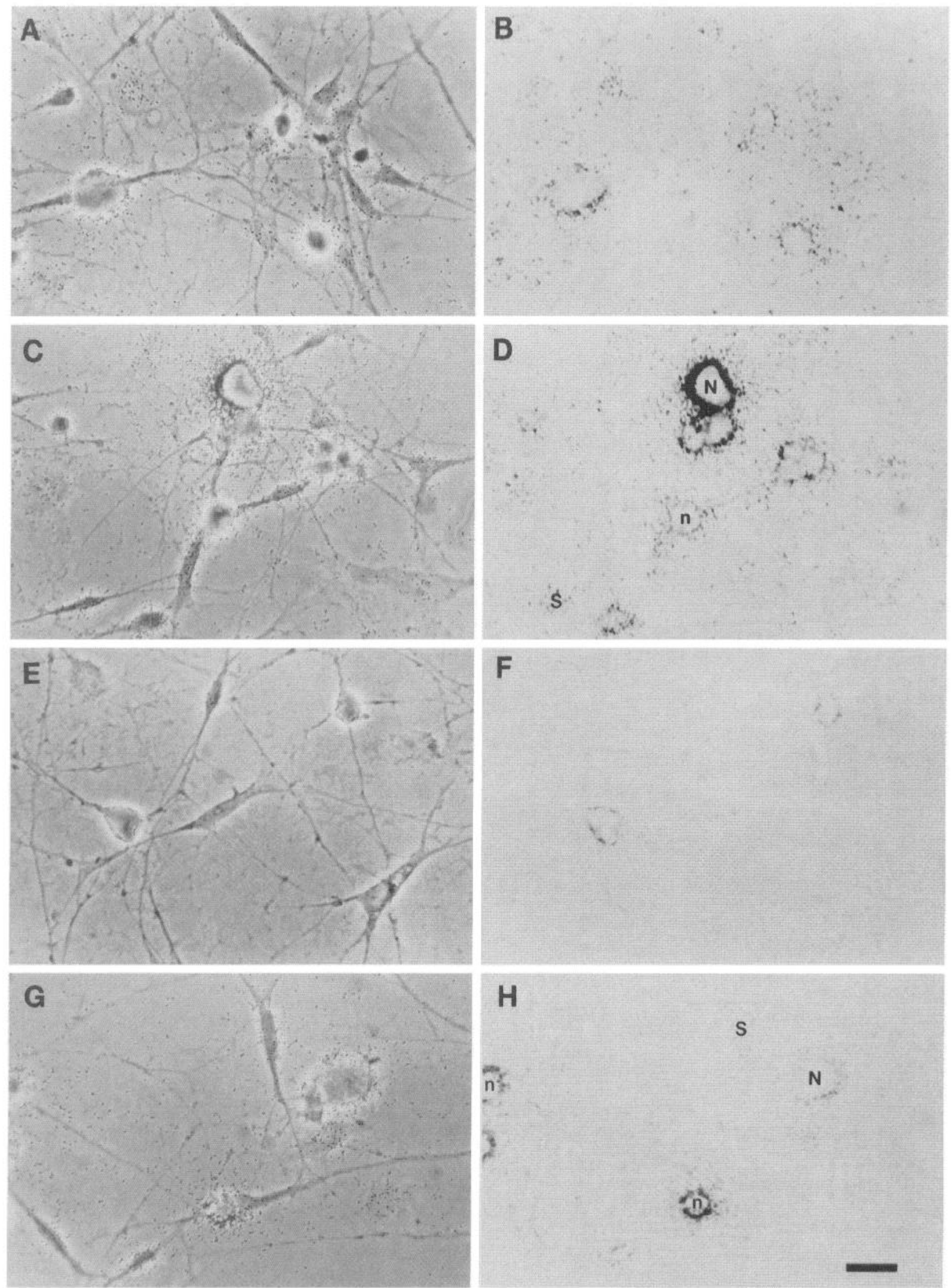

Figure 7. In situ hybridization of cultured dissociated DRG cells. Cultures of DRG cells grown for $20-24$ hr were fixed and subjected to in situ hybridization using ${ }^{35}$ S-labeled sense $(A, B, E, F)$ or antisense $(C, D, G, H)$ oligonucleotide probes for uPA $(A-D)$ or tPA $(E-H)$ mRNAs. $B, D$, $F$, and $H$ are the corresponding bright-field images of the phase-contrast micrographs shown in $A, C, E$, and $G$. D, uPA mRNA is expressed mainly by large neurons $(N)$ with little signal detected in small neurons $(n)$ and Schwann cells $(S)$. $H$, tPA mRNA signal is visible in small neurons $(n)$ with only background levels of signal visible near large neurons $(N)$ and Schwann cells $(S)$. Scale bar, $20 \mu \mathrm{m}$. 


\begin{tabular}{|c|c|c|}
\hline $\begin{array}{l}\text { Plasminogen } \\
\text { activator }\end{array}$ & $\begin{array}{l}\text { Large neurons } \\
(\geq 20 \mu \mathrm{m})\end{array}$ & $\begin{array}{l}\text { Small neurons } \\
(<12 \mu \mathrm{m})\end{array}$ \\
\hline uPA mRNA & $70.7 \pm 5.81^{a}$ & $12.8 \pm 2.04$ \\
\hline tPA mRNA & $11.6 \pm 2.19$ & $56.8 \pm 4.74^{b}$ \\
\hline
\end{tabular}

Values were obtained from digitized images of in situ hybridization results and are expressed in arbitrary units as average grain density (mean $\pm \mathrm{SEM} ; n=10$ ).

${ }^{a} p<0.0001$ (paired $t$ test) versus small neurons.

${ }^{b} p<0.0001$ (paired $t$ test) versus large neurons.

Clearly, additional studies characterizing the underlying mechanisms that are responsible for regulating the expression of PA system components are warranted.

Using in situ hybridization, we found that uPA mRNA is expressed predominantly by large sensory neurons in DRG cultures, whereas tPA is synthesized primarily by a subpopulation of small neurons. Large DRG neurons are considered to be of type A and are distinguished from the smaller type B neurons by morphological features and cytochemical markers (Sommer et al., 1985). Type A and type B neurons can be further subclassified according to their ultrastructural charac- teristics and additional cytochemical properties, such as the expression of the calcium-binding protein calbindin D and the neuropeptide substance P (Ninomiya et al., 1994). Although beyond the scope of this study it is tempting to speculate that, in vivo, the difference in the physical properties of the two PAs and their differential expression in cells may serve as a means of providing two separate directional cues for cells as they migrate through extracellular matrix barriers during development or regeneration. In this regard, it is of interest that projections from large type A neurons have been shown to follow paths that are distinct from those of type B neurons. Type A neurons connect specifically with rapidly adapting mechanoreceptors such as muscle spindles, whereas type B neurons have less-defined targets and have projections that have been found to be diffusely innervated throughout skeletal muscle and skin (Duc et al., 1993). Differences in termination sites also exist at the spinal cord. From entry at the dorsal surface of the cord, muscle afferent axons from DRG project to the ventral horn, whereas cutaneous afferent axons terminate in the dorsal-most region of the cord near the site of entry (Christensen and Perl, 1970; Light and Perl, 1979).

In situ hybridization studies also revealed that whereas uPA is synthesized predominantly by sensory neurons, uPAR is generated by both neurons and Schwann cells. Thus, in cultures
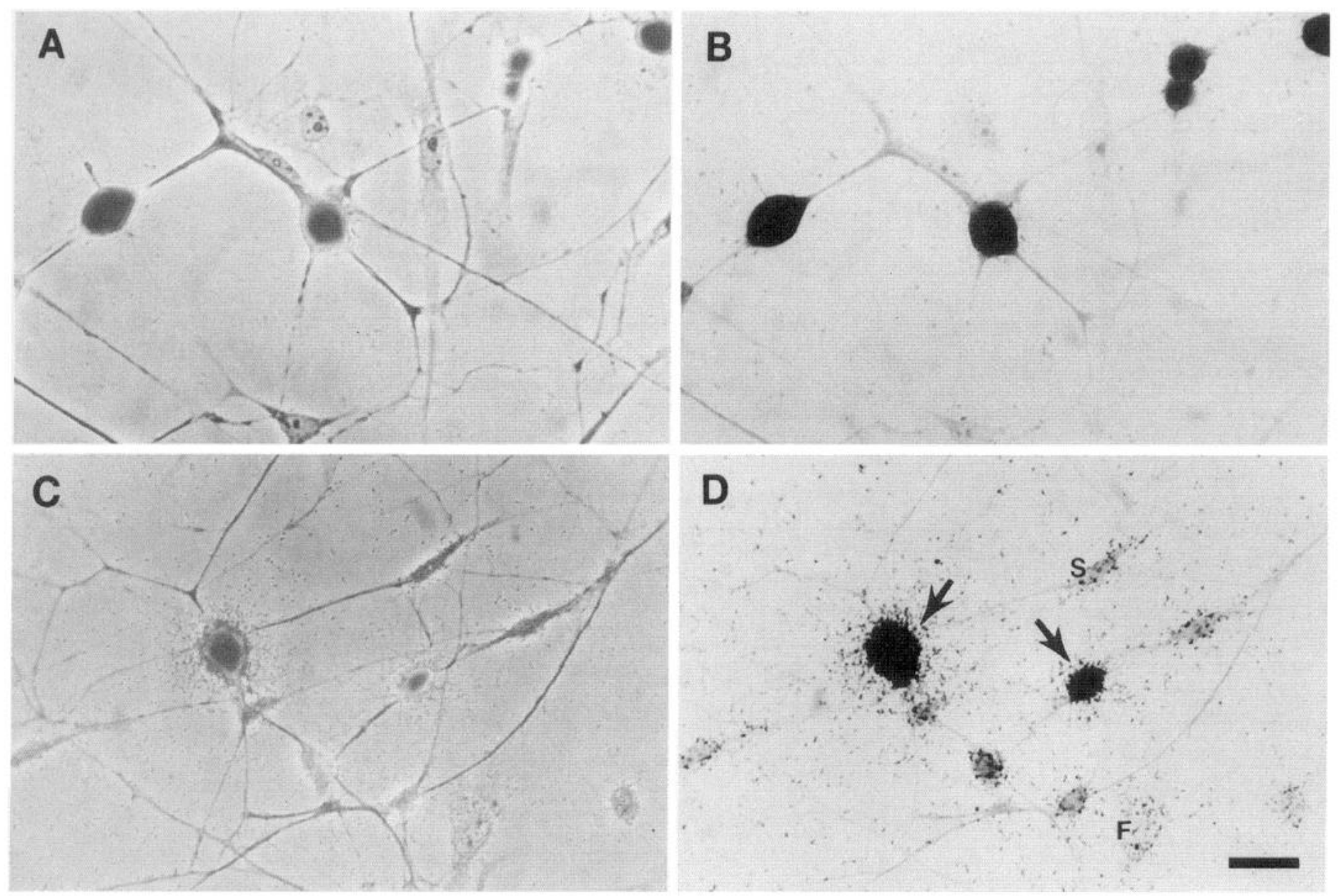

Figure 8. Double-labeling of cultured dissociated DRG cells. Cultures of dissociated DRG cells were grown for 24 hr, fixed, and incubated with ${ }^{35}$ S-labeled uPAR sense $(A$ and $B)$ or antisense $(C$ and $D)$ oligonucleotide probes. The cultures were then washed and treated for immunostaining of neuron-specific enolase. Bright-field images $(B$ and $D)$ of phase-contrast micrographs $(A$ and $C)$ demonstrate that neurons, but not Schwann cells or fibroblasts, are immunostained. In situ hybridization using uPAR antisense probes $(D)$ detects uPAR mRNA in all neurons (arrows), with weaker expression in Schwann cells $(S)$ and also fibroblasts $(F)$. Scale bar, $20 \mu \mathrm{m}$. 
of dissociated DRG cells, a paracrine mechanism may exist for Schwann cell binding of neuron-secreted uPA. A similar mechanism has been described for human colon tumors in which UPA mRNA is localized in stromal cells and UPAR mRNA is found primarily in tumor cells (Pyle et al., 1991). It has been concluded from these findings that in some instances tumor cells may stimulate the production of uPA by adjacent stromal cells and use the protease to facilitate tissue invasion. In analogy with this system, the possibility should be considered that the motility that is ascribed to cultured Schwann cells interacting with neuronal cells may in part be induced and facilitated by uPA synthesized by the neurons themselves.

Our observation that PA system component mRNA and activity levels are modulated during differentiation of DRG dissociated cells is in support of results reported by others implicating the PA system in the development of the PNS. From in situ hybridization analysis of rat spinal cord sections, Sumi et al. (1992) detected uPA mRNA expression in motor neurons and DRG sensory neurons as early as embryonic day 12.5 (E12.5), a stage during which axonal growth is initiated, and found that expression is sustained in adult stage P3 neurons. At E10.5, during which stage motor and sensory neurons have yet to develop, no uPA mRNA signals could be detected in spinal cord or in adjacent regions. In pilot studies, we have attempted a more quantitative analysis of such studies using competitive PCR to measure the absolute amount of PA system component mRNAs in isolated mouse DRGs obtained from E19, P0, P2, and P4 (data not shown). Although we have not detected any significant change in tPA, uPA, or uPAR mRNA at these stages, it should be mentioned that these studies are complicated at earlier stages by the lack of tissue development, which unfortunately prevents definitive isolation of DRGs. In analogy to the mRNA increases we observed in cultured DRG cells, it seems likely that increases in PA system component expression in DRGs in vivo would occur at stages of development earlier than E19, during events such as neural crest cell migration and/or the onset of axonal outgrowth from sensory neurons.

In summary, we have shown that a positive correlation exists between axonal outgrowth and morphological differentiation of cultured dissociated cells from DRG and the enhanced expression of PA system componcnts. Wc have also found that uPA and tPA are differentially expressed by subpopulations of cultured neuronal cells from DRG, suggesting a possible role in axonal guidance during development. The expression of uPAR by virtually all cells in DRG cultures and the finding that uPA is produced by only a subset of the cultured cells suggest that urokinase may exhibit paracrine binding in intact DRG in vivo. The development of the quantitative PCR method described in this study should serve as a valuable tool for future studies investigating the expression of PA system components in nervous system growth and regeneration.

\section{REFERENCES}

Becker-Andrc M, IJahlbrock K (1989) Absolutc mRNA quantification using the polymerase chain reaction (PCR). A novel approach by a PCR aided transcript titration assay (PATTY). Nucleic Acids Res 17:9437-9446.

Behrendt N, Ronne E, Ploug M, Petri T, Lober D, Nielsen LS, Schleuning W-D, Blasi F, Appella E, Dano K (1990) The human receptor for urokinase plasminogen activator. NH2-terminal amino acid sequence and glycosylation variants. J Biol Chem 265:6453-6460.
Christensen BN, Perl ER (1970) Spinal neurons specifically excited by noxious or thermal stimuli: marginal zone of the dorsal horn. $J$ Neurophysiol 33:293-307.

Clark MB, Zeheb R, White TK, Bunge RP (1991) Schwann cell plasminogen activator is regulated by neurons. Glia 4:514-528.

Duc C, Barakat-Walker I, Droz B (1993) Calbindin D-28k- and substance $P$-immunoreactive primary sensory neurons: peripheral projections in chick hindlimbs. J Comp Neurol 334:151-158.

Gilliland G, Perrin S, Blanchard K, Bunn HF (1990) Analysis of cytokine mRNA and DNA: detection and quantitation by competitive polymerase chain reaction. Proc Natl Acad Sci USA 87:2725-2729.

Hajjar KA, Jacovina AT, Chacko J (1994) An endothelial cell receptor for plasminogen/tissue plasminogen activator. I. Identity with annexin II. J Biol Chem 269:21191-21197.

Hawkins RL, Seeds NW (1986) Effect of proteases and their inhibitors on neurite outgrowth from mouse sensory ganglia. Brain Res 398:63-70.

Hawkins RL, Seeds NW (1989) Protease inhibitors influence the direction of neurite outgrowth. Dev Brain Res 45:203-209.

Heussen C, Dowdle EB (1980) Electrophoretic analysis of plasminogen activators in polyacrylamide gels containing SDS and co-polymerized substrates. Anal Biochem 120:196-202.

Huarte J, Belin A, Vassalli A, Strickland S, Vassalli J-D (1987) Meiotic maturation of mouse oocytes triggers the translation and polyadenylation of dormant tissue-type plasminogen activator mRNA. Genes Dev $1: 1201-1211$.

Kalderon N (1984) Schwann cell proliferation and localized proteolysis: expression of plasminogen-activator activity predominates in the proliferating cell populations. Proc Natl Acad Sci USA 81:7216-7220.

Kirchheimer JC, Wojta J, Christ G, Binder BR (1987) Proliferation of a human epidermal tumor cell line stimulated by urokinase. FASEB J $1: 125-128$.

Krystosck A, Sceds NW (1981) Plasminogen activator relcase at the neuronal growth cone. Science 213:1532-1534.

Krystosek A, Seeds NW (1984) Peripheral neurons and Schwann cells secrete plasminogen activator. J Cell Biol 98:773-777.

Krystosck A, Verrall S, Seeds NW (1988) Plasminogen activator secretion in relation to Schwann cell activities. Int J Dev Neurosci 6:483-493.

Light AR, Perl ER (1979) Reexamination of the dorsal root projection to the spinal dorsal horn including observations on the differential termination of coarse and fine fibers. J Comp Neurol 186:117-132.

McGuire PG, Alexander SM (1993) Urokinase production by embryonic endocardial-derived cells: regulation by substrate composition. Dev Biol 155:442-451.

Ninomiya T, Barakat-Walker I, Droz B (1994) Neuronal phenotypes in mouse dorsal root ganglion cell cultures: enrichment of substance $P$ and calbindin D-28k expressing neurons in a defined medium. Int J Dev Neurosci 12:99-106.

Nykjaer A, Petersen CM, Moller B, Jensen PA, Moestrup SK, Holtet TL, Etzerodt M, Thogersen HC, Munch M, Andreasen PA, Gilemann J (1992) Purified $\alpha_{2}$-macroglobulin receptor/LDL receptor-related protein binds urokinase-plasminogen activator inhibitor type-1 complex: evidence that the $\alpha_{2}$-macroglobulin receptor mediates cellular degradation of urokinase receptor-bound complexes. J Biol Chem 267:11543-14516.

Olson D, Pollanen J, Hoyer-Hansen G, Ronne E, Sakaguchi K, Wun T- C, Appella E, Dano K, Blasi F (1992) Internalization of the urokinaseplasminogen activator inhibitor type-1 complex is mediated by the urokinasc reccptor. J Biol Chem 267:9129-9133.

Orth K, Madison EL, Gething M-J, Sambrook JF, Herz J (1992) Complexes of t-PA and its serpin inhibitor PAI-1 are internalized via the LRP $/ \alpha_{2}$-macroglobulin receptor. Proc Natl Acad Sci USA 89:7422-7426.

Pittman RN (1985) Release of plasminogen activator and a calciumdependent metallo-protease from cultured sympathetic and sensory neurons. Dev Biol 110:91-101.

Ploug M, Ronne E, Behrendt N, Jensen AL, Blasi F, Dano K (1991) Cellular receptor for urokinase plasminogen activator. Carboxylterminal processing and membrane anchoring by glycosylphosphatidylinositol. J Biol Chem 266:1926-1933.

Pyle C, Kristensen P, Ralfkiaer E, Grondahl-Hansen J, Eriksen J, Blasi F, Dano K (199I) Urokinase-type plasminogen activator is expressed in stromal cells and its receptor in cancer cells at invasive foci in human colon adenocarcinomas. Am J Pathol 138:1059-1067.

Rogister B, Leprince P, Pettman B, Labourdette G, Sensenbrener M, Moonen $G$ (1988) Brain basic fibroblast growth factor stimulates the 
release of plasminogen activators by newborn rat cultured astroglial cells. Neurosci Lett 91:321-326.

Saksela O, Rifken DB (1988) Cell-associated plasminogen activation: regulation and physiological functions. Annu Rev Cell Biol 4:93-126.

Sappino A-P, Madani R, Huarte J, Belin D, Kiss JZ, Wohlwend A, Vassalli J-D (1993) Extracellular proteolysis in the adult murine brain. J Clin Invest 92:679-685.

Seeds NW, Verrall S, Friedman G, Hayden S, Gadotti D, Haffke S, Christensen K, Gardner B, McGuire P, Krystosek A (1992) Plasminogen activators and plasminogen activator inhibitors in neural development. Ann N Y Acad Sci 667:32-40.

Shoffner JM, Lott MT, Lezza AMS, Seibel P, Ballinger SW, Wallace DC (1990) Myoclonic epilepsy and ragged-red fiber disease (MERRF) is associated with a mitochondrial DNA tRNA ${ }^{\mathrm{Ly}}$ mutation. Cell 61:931-937.
Sommer EW, Kazimierczak J, Droz B (1985) Neuronal subpopulations in the dorsal root ganglia of the mouse as characterized by combination of ultrastructural and cytochemical features. Brain Res 346:310-326.

Suh TT, Nerlov C, Dano K, Degen JL (1994) The murine urokinase-type plasminogen activator receptor gene. J Biol Chem 269:25992-25998.

Sumi Y, Dent MAR, Owen DE, Seeley PJ, Morris RJ (1992) The expression of tissuc- and urokinase-type plasminogen activators in neural development suggests different modes of proteolytic involvement in neuronal growth. Development 116:625-637.

Tranque P, Naftolin F, Robbins R (1994) Differential regulation of astrocyte plasminogen activators by insulin-like growth factor-I and epidermal growth factor. Endocrinology 134:2606-2613.

Verrall S, Seeds NW (1989) Characterization of ${ }^{125}$ I-tissue plasminogen activator binding to cerebellar granule neurons. J Cell Biol 109: 265-271. 